\title{
A new stability indicating RP-UPLC method for simultaneous estimation of Doravirine, Lamivudine and Tenofovir disoproxil fumarate in bulk and their combined pharmaceutical formulation
}

\author{
Swetha Addanki ${ }^{*}$ (ID and B. Ramya Kuber ${ }^{2}$
}

\begin{abstract}
Background: To establish a simple, sensitive, accurate, precise, efficient, economical RP-UPLC method for simultaneous estimation of Doravirine, Lamivudine and Tenofovir disoproxil fumarate in bulk and their combined pharmaceutical formulations. Optimization of Chromatographic separation was achieved on analytical column HSS C18 $(100 \times 2.1 \mathrm{~mm}, 1.8 \mu)$ maintained at temperature $30^{\circ} \mathrm{C}$ and mobile phase consisting of $0.01 \mathrm{~N}$ Potassium dihydrogen orthophosphate buffer ( $\mathrm{pH}-4.8$ ) and acetonitrile in the ratio $60: 40 \mathrm{v} / \mathrm{v}$ and at a flow rate $0.3 \mathrm{~mL} / \mathrm{min}$ in isocratic mode. The injection volume was set as $1 \mu$ detection wavelength is $260 \mathrm{~nm}$. The proposed method validation was done as per International Council on Harmonization Q2 (R1) guidelines.

Results: Doravirine, Lamivudine and Tenofovir disoproxil fumarate were eluted at retention times of 1.2, 1.5, and $1.8 \mathrm{~min}$ respectively. The proposed method was identified an excellent linearity over concentration range of $12.5-75.0 \mu \mathrm{g} / \mathrm{mL}$ for Doravirine and $37.5-225.0 \mu \mathrm{g} / \mathrm{mL}$ for Lamivudine and 37.5-225.0 $\mu \mathrm{g} / \mathrm{mL}$ for Tenofovir disoproxil fumarate. The percentage relative standard deviation for intra-day and inter-day precision of the present method was less than 2\% for Doravirine, Lamivudine and Tenofovir disoproxil fumarate. Accuracy of the present method was evaluated by recovery studies which were in the range of $99.62-99.88 \%$ for Doravirine and $98.78-99.44 \%$ for Lamivudine and $99.67-100.52 \%$ for Tenofovir disoproxil fumarate. The limit of detection and limit of quantification were found to be $0.249 \mu \mathrm{g} / \mathrm{mL}$ and $0.756 \mu \mathrm{g} / \mathrm{mL}$ for Doravirine and $0.24 \mu \mathrm{g} / \mathrm{mL}$ and $0.727 \mu \mathrm{g} / \mathrm{mL}$ for Lamivudine and $0.797 \mu \mathrm{g} / \mathrm{mL}$ and $2.966 \mu \mathrm{g} / \mathrm{mL}$ for Tenofovir disoproxil fumarate. Forced degradation studies were carried out under various stress conditions like acid, base, peroxide, thermal, photo and neutral conditions.
\end{abstract}

Conclusions: The present method makes sure about no degraded impurity peak interference at the retention time of analyte peak hence can be applied for quality control investigation of Doravirine, Lamivudine and Tenofovir disoproxil fumarate in bulk and pharmaceutical formulations.

Keywords: Doravirine, Lamivudine, Tenofovir disoproxil fumarate, Method validation, Forced degradation, Reverse phase ultra-performance liquid chromatographic method

\footnotetext{
*Correspondence: swetha.addanki06@gmail.com

1 Department of Pharmaceutical Analysis, IPT, SPMVV, Tirupati, Andhra

Pradesh 517501, India

Full list of author information is available at the end of the article
} 


\section{Background}

Doravirine (DOR) is a synthetic derivative of pyridinone moiety significantly hinders the function of the non-nucleoside reverse transcriptase which is responsible for integration and replication of genome of the Human immune virus [1-3]. Chemically DOR is 3-chloro-5-[1-[(4-methyl-5-oxo1H-1,2,4-triazol-3-yl) methyl]-2-oxo-4-(trifluoromethyl) pyridin-3-yl] oxybenzonitrile. Triphosphate of LMV (3TCTP) is the competitive inhibitor of nucleoside reverse transcriptase [4-6]. LMV chemically is 4-amino-1-[(2R, 5S)2-(hydroxyl methyl)-1, 3-oxathiolan-5-yl]-1, 2-dihydropyrimidin-2-one. Tenofovir is the active moiety of TDF ceases the replication of viral genome by inhibiting the nucleoside reverse transcriptase competitively [7-9]. TDF chemically is 1-(6-aminopurine-9-yl) propan-2 yl] oxy methyl-(propan2-yl oxy carbonyl oxy methoxy) phosphoryl] Oxy methyl propan -2yl carbonate. DELSTRIGO ${ }^{\mathrm{TM}}$ is a recently approved combined tablet dosage form comprising three active moieties including Doravirine (DOR), Lamivudine (LAM) and Tenofovir disproxil fumarate (TDF). It is a highly potent regimen to improve the quality of life and survival span of HIV-I patients. The chemical structures of DOR, LAM and TDF were given in Fig. 1.

As per literature survey, a quite few analytical methods were disclosed for analysis of DOR, LMV, TDF as single entities. A few analytical methods were developed for simultaneous analysis of LMV with other antiviral agents and TDF with other antiviral agents [10-16]. Certain analytical methods were described to estimate TDF, LMV with other antiretroviral agents [17-26]. An immense exploration of literature exposed that only two HPLC methods were recently reported for simultaneous analysis of DOR, LMV and TDF in a tablet dosage form $[27,28]$. In the reported HPLC methods, many significant drawbacks were observed like retention time of LAM (2.45 $\mathrm{min})$ and TDF (7.3 $\mathrm{min})$ and DOR (8.79 $\mathrm{min}$ ) was longer and more solvent consumption. No UPLC method was noticed for simultaneous estimation of DOR, LAM and TDF in a combined dosage form. Due to lack of methods, there is a scope to develop an economical, efficient UPLC method for simultaneous estimation of DOR, LAM and TDF with high sensitivity and better resolution of drug analytes in the mixture. Hence, current method aimed to develop UPLC method for synchronized estimation of DOR, LAM, TDF analytes in blended pure powder and in film coated tablet dosage form.

\section{Methods}

\section{Pure samples}

The pure form of TDF (99.17\%), DOR (99.3\%) and LMV (99.4\%) were procured from Spectrum pharma research solutions, Hyderabad.

\section{Formulation}

The DELSTRIGO ${ }^{\mathrm{TM}}$ (100 mg of Doravirine, $300 \mathrm{mg}$ of Lamivudine, and $300 \mathrm{mg}$ of Tenofovir disoproxil fumarate) tablets were purchased from local marketing agency upon request.

\section{Chemicals and reagents}

All the solvents of HPLC grade were procured from local distributor of Merck India Limited, Mumbai. All the chemicals of analytical grade and HPLC grade water were acquired from the Finar chemical distributor.

\section{Instrumentation}

The current method was carried out using WATERS Acquity UPLC system which is equipped with Tunable UV detector and HSS $(\mathrm{C} 18100 \times 2.1 \mathrm{~mm}, 1.8 \mu)$ column used as a stationary phase. Empower 2 software was used to process and integrate the data.

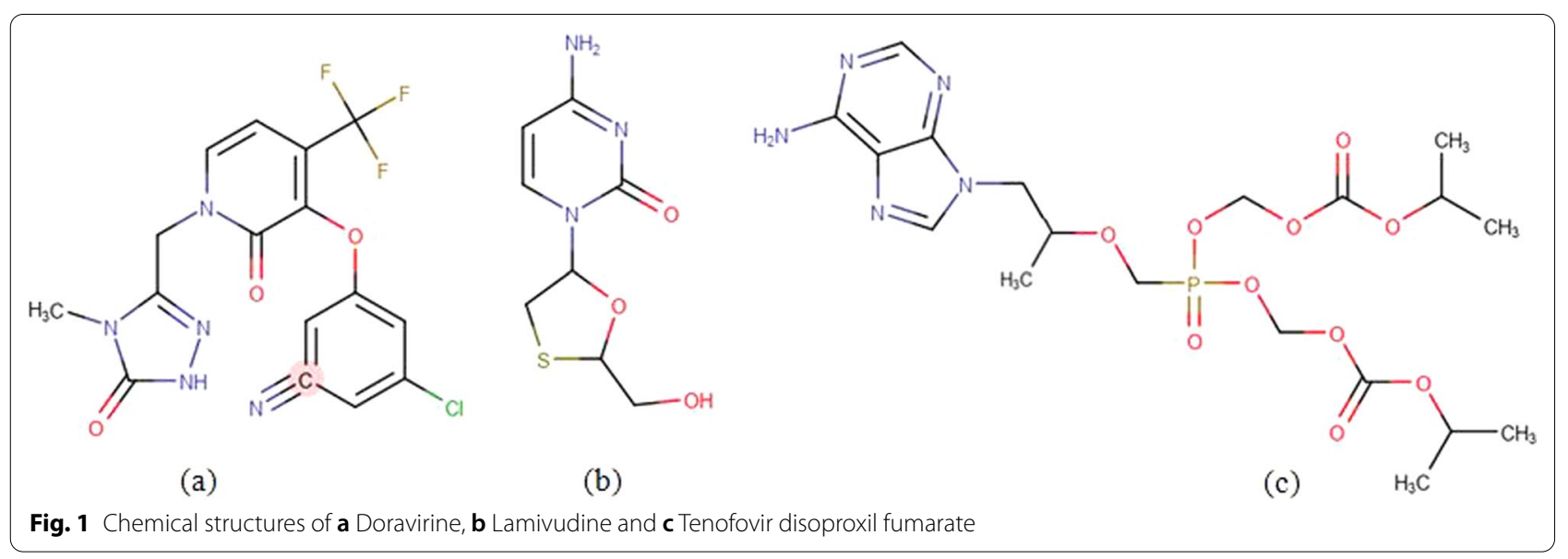




\section{Preparation of standard solution}

$25 \mathrm{mg}$ of DOR, $75 \mathrm{mg}$ of LAM and $75 \mathrm{mg}$ of TDF were accurately weighed and transferred into $50 \mathrm{~mL}$ volumetric flask and dissolve the above analytes with diluent consisting of equal volumes of water and $0.01 \mathrm{~N}$ Potassium dihydrogen ortho phosphate and make up to the volume with the diluent to get the standard stock solution concentration consisting of $500 \mu \mathrm{g} / \mathrm{mL}$, $1500 \mu \mathrm{g} / \mathrm{mL}$ and $1500 \mu \mathrm{g} / \mathrm{mL}$ for DRV, LMV and TDF respectively. Dilute $1 \mathrm{~mL}$ of above solution to $10 \mathrm{~mL}$ with diluent to get working standard solution having concentration of $50 \mu \mathrm{g} / \mathrm{mL}, 150 \mu \mathrm{g} / \mathrm{mL}$ and $150 \mu \mathrm{g} / \mathrm{mL}$ for DOR, LAM and TDF respectively.

\section{Preparation of sample solution}

The tablet (Delstrigo ${ }^{\text {TM }}$ consisting of $300 \mathrm{mg}$ of Tenofovir disoproxil fumarate, $300 \mathrm{mg}$ of Lamivudine, and $100 \mathrm{mg}$ of Doravirine) powder is equivalent to $75 \mathrm{mg}$ of LAM $75 \mathrm{mg}$ of TDF and $25 \mathrm{mg}$ of DRV were accurately weighed and placed in $50 \mathrm{~mL}$ volumetric flask. Above contents of analytes were dissolved with diluents consisting of equal volumes of water and $0.01 \mathrm{~N}$ Potassium dihydrogen ortho phosphate in equal proportions. $1 \mathrm{~mL}$ of the above solution is further diluted with $10 \mathrm{~mL}$ diluent to get a solution having concentration $150 \mu \mathrm{g} / \mathrm{mL}, 150 \mu \mathrm{g} / \mathrm{mL}$ and $50 \mu \mathrm{g} / \mathrm{mL}$ for LAM, TDF and DOR respectively. The possible particulate matter in sample was eliminated by using $0.45 \mu \mathrm{m}$ Nylon filters.

\section{Method development Chromatographic method conditions:}

The current method was carried out by using WATERS UPLC system with Tunable UV detector. DOR, LAM and TDF analytes were successfully separated by using HSS $(\mathrm{C} 18100 \times 2.1 \mathrm{~mm}, 1.8 \mu)$ column and with mobile phase consisting of $0.01 \mathrm{~N}$ Potassium dihyrogen ortho phosphate (pH-4.8) and Acetonitrile in 60:40 v/v pumping at $0.3 \mathrm{~mL} / \mathrm{min}$ flow rate. Analytes were detected at a wavelength $260 \mathrm{~nm}$. Both analytical column and injection device were maintained at the same temperature $30{ }^{\circ} \mathrm{C}$. Before application of sample and mobile phase into the instrument, filtered through $0.45 \mu$ Nylon filters to dispose of particulate matter in it.

\section{Method validation}

The following method has been validated using below mentioned validation parameters according to ICH Q2 (R1) guidelines specifications [29].

\section{System suitability}

The system suitability of the proposed method has been validated by injecting 6 replicates of standard solution $(150 \mu \mathrm{g} / \mathrm{mL}$ of LAM, $150 \mu \mathrm{g} / \mathrm{mL}$ of TDF and $50 \mu \mathrm{g} / \mathrm{mL}$ of DOR) into UPLC system. System suitability parameters like resolution (R), number of theoretical plates $(\mathrm{N})$, tailing factor $(\mathrm{T})$ were assessed by determining the percentage relative standard deviation (\%RSD) of parameters for the recorded chromatograms.

\section{Linearity}

Linearity of the method assures a direct proportional relationship between input concentrations and the obtained output peak area responses. Linearity was estimated by assessing the correlation coefficient ( $\mathrm{r} 2$ ) value for the triplicates of the series of working standard solution concentrations about 37.5, 75.0, 112.5, 150.0, 187.5, $225.0 \mu \mathrm{g} / \mathrm{mL}$ for both LAM and TDF and 12.5, 25.0, $37.5,50.0,62.5,75.0 \mu \mathrm{g} / \mathrm{mL}$ for DOR, by plotting a linear response curve in between series of concentrations and obtained peak areas mentioned for each analyte.

\section{Sensitivity}

The limit of detection (LOD) and limit of quantification (LOQ) were assessed by following formulae

$$
\begin{aligned}
& \mathrm{LOD}=3.3 \sigma / \mathrm{S} \\
& \mathrm{LOQ}=10 \sigma / \mathrm{S}
\end{aligned}
$$

where $\sigma$ standard deviation (SD) obtained from the intercept of linear plot $(n=3)$. $S$ average slope of the linear plot $(n=3)$.

\section{Solution stability}

Solution stability was performed by using standard solution stored at room temperature and evaluate the solution at specific intervals of time for $72 \mathrm{~h}$.

\section{Specificity}

Specificity of the method was evaluated by analysis of different analytes which are not interfered by the presence of other impurities or degradation products. Specificity was determined by giving subsequent injections of blank, standard solution and placebo spiked in standard solution and make sure that no interferences from blank and placebo at the retention time of DOR, LAM, TDF.

\section{Precision}

Precision parameter represents the closeness relationship established among the obtained responses of same 
sample under similar conditions. It was done by giving six replicate injections of standard solutions in the same day (intra-day precision) and same standard solution injected two times in a day for three continuous days under similar conditions (inter-day precision). \%RSD was calculated for peak areas of recorded chromatograms.

\section{Accuracy}

Percentage recovery method was adopted to ensure the accuracy of the proposed method, in which at three percentage levels sample solution was spiked into standard solution. Analysis was done by triplicate injections of each level spiked solution. At the three different levels, mean percentage recovery of DOR, LAM, TDF was calculated.

\section{Robustness}

Robustness parameter assures that to maintain originality of the method to produce response by modifying certain method conditions intentionally. In the proposed method, to validate the robustness parameter slight variations employed in method conditions are mobile phase ratio $( \pm 10 \%)$, flow rate $( \pm 10 \% \mathrm{~mL} / \mathrm{min})$ and temperature $\left( \pm 5{ }^{\circ} \mathrm{C}\right) . \%$ RSD was assessed for the peak areas of recorded chromatograms.

\section{Stability indicating studies}

Forced degradation studies were conducted as per Q1A, QIB and Q2B guidelines of ICH [29]. Stability indicating studies were conducted with standard drug solution in order to assess the stability indicating power of the method and to predict the essential requirements of storage conditions for pure drug and its dosage form.

\section{Acid degradations studies}

In this study, equal volumes of standard stock solution $(1.5 \mathrm{mg} / \mathrm{mL}$ of LAM, $1.5 \mathrm{mg} / \mathrm{mL}$ of TDF and $0.5 \mathrm{mg} / \mathrm{mL}$ of DOR) and $2 \mathrm{~N} \mathrm{HCl}$ solution were mixed and the resultant solution was refluxed for $60 \mathrm{~min}$ at $60{ }^{\circ} \mathrm{C}$. Neutralize the obtained solution with $2 \mathrm{~N} \mathrm{NaOH}$ and dilution was made to accomplish concentration in the order of $150 \mu \mathrm{g} /$ $\mathrm{mL}, 150 \mu \mathrm{g} / \mathrm{mL}$ and $50 \mu \mathrm{g} / \mathrm{mL}$ for TDF, LAM and DOR. Inject $1 \mu \mathrm{l}$ of above solution into UPLC system to assess the percentage of drugs degraded under acid degradation conditions from the obtained chromatograms.

\section{Alkali degradation studies}

In this alkaline study, equal volumes of standard stock solution and $2 \mathrm{~N} \mathrm{NaOH}$ were mixed properly and reflux the resultant solution for $60 \mathrm{~min}$ at $60{ }^{\circ} \mathrm{C}$. The obtained solution was neutralized with $2 \mathrm{~N} \mathrm{HCl}$ and diluted further to obtain concentration of $150 \mu \mathrm{g} /$ $\mathrm{mL}, 150 \mu \mathrm{g} / \mathrm{mL}$ and $50 \mu \mathrm{g} / \mathrm{mL}$ for TDF, LAM and DOR respectively. From the above solution $1 \mu \mathrm{l}$ was injected into UPLC system and the percentage of drugs degraded was assessed from the attained chromatograms under alkaline conditions.

\section{Oxidative degradation studies}

In this study, standard stock solution and $20 \%$ hydrogen peroxide solution were mixed in equal proportion and reflux for $60 \mathrm{~min}$ at $60{ }^{\circ} \mathrm{C}$. The obtained solution was further diluted to attain $150 \mu \mathrm{g} / \mathrm{mL}, 150 \mu \mathrm{g} / \mathrm{mL}$ and $50 \mu \mathrm{g} / \mathrm{mL}$ for TDF, LAM and DOR respectively. A volume of $1 \mu \mathrm{l}$ was introduced into UPLC system and evaluate the percentage of drugs degraded from the resultant chromatograms.

\section{Photo degradation studies}

In this study, expose the standard stock solution to a wavelength of $254 \mathrm{~nm}$ in UV chamber for $72 \mathrm{~h}$ with dark control. The above solution was to accomplish concentration of $150 \mu \mathrm{g} / \mathrm{mL}, 150 \mu \mathrm{g} / \mathrm{mL}$ and $50 \mu \mathrm{g} / \mathrm{mL}$ for TDF, LAM and DOR in that order. $1 \mu \mathrm{l}$ of the diluted solution was introduced into the UPLC system and assessed the percentage of the drug degraded from the attained chromatograms.

\section{Thermal degradation studies}

In this study, held $5 \mathrm{~mL}$ of the standard solution in the oven at $105^{\circ} \mathrm{C} / 75 \% \mathrm{RH}$ for $6 \mathrm{~h}$. A volume of $1 \mu \mathrm{l}$ resultant solution was injected into the UPLC system and the percentage of the drug degraded was assessed from the attained chromatograms under thermal degradation conditions.

\section{Neutral degradation studies}

In this degradation study, standard stock solution and Milli-Q water were mixed properly in equal volumes to get the homogenous solution. Dilute the above solution was further to attain concentration of $150 \mu \mathrm{g} / \mathrm{mL}, 150 \mu \mathrm{g} /$ $\mathrm{mL}$ and $50 \mu \mathrm{g} / \mathrm{mL}$ for TDF, LMV and DRV respectively. $1 \mu \mathrm{l}$ of above solution was introduced and recorded the chromatograms to evaluate the percentage of the drug was degraded under neutral conditions.

\section{Application of the method to Marketed formulation}

The current method has been applied to find out the percentage purity of commercial tablets (DELSTRIGO ${ }^{\mathrm{TM}}$ ) by injecting subsequent injections of same concentration of both standard and sample solutions consecutively. The percentage purity of every analyte was evaluated from 


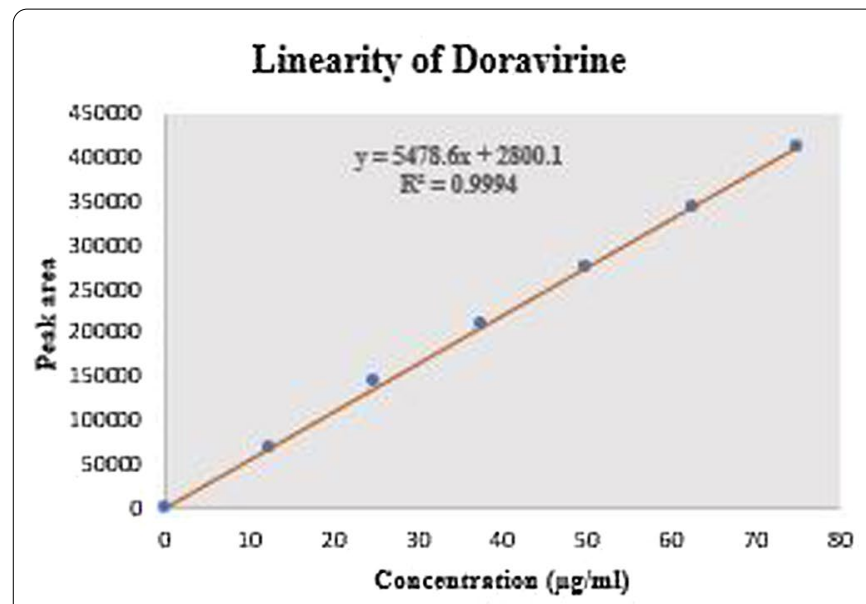

(A)

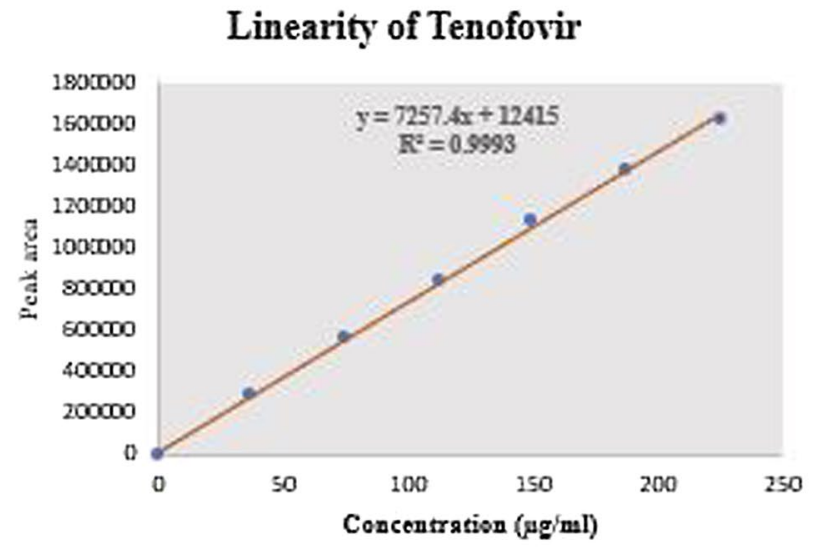

(C)

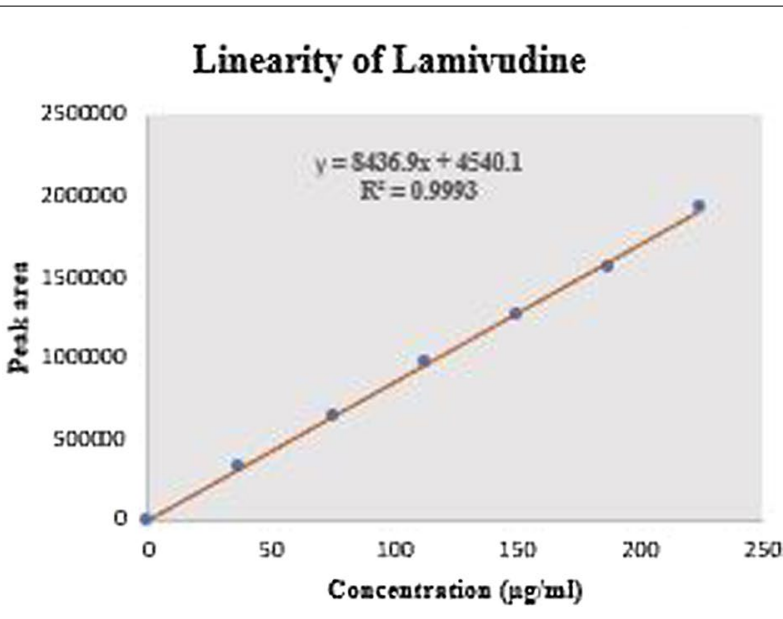

(B)

\section{(A) Doravirine \\ (B) Lamivudine \\ (C) Tenofovir disoproxil fumarate}

Fig. 2 Chromatogram of the standard solution

the peak areas of three analytes in both standard and sample solution.

\section{Results}

\section{Method optimization}

An efficient optimized method was achieved from trial-and-error method by using different columns and various mobile phase combinations with different flow rates. Finally, DOR and LAM, TDF were successfully separated with fine resolution at retention time of $1.2 \mathrm{~min}, 1.5 \mathrm{~min}$ and $1.8 \mathrm{~min}$ respectively (Fig. 2) by using HSS $(\mathrm{C} 18100 \times 2.1 \mathrm{~mm}, 1.8 \mu)$, mobile phase composition of buffer and Acetonitrile in 60:40 v/v at a flow rate of $0.3 \mathrm{~mL} / \mathrm{min}$ and a wavelength of $260 \mathrm{~nm}$ was selected to detect three different analytes (Table 1).

\section{Method validation} System suitability

The statistical data obtained from the chromatograms of six replicate injections of standard solution proved that \%RSD of all parameters like tailing factor, theoretical plate number, resolution have been fulfilled the acceptable limits of various regulatory bodies [30]. The obtained system suitability data were shown in Table 2.

\section{Linearity}

The regression equation obtained from the linearity data of DOR is $(Y=5478.6 x+2800.1)$ and for LAM is $y=8436.9 x+4540.1$ and for TDF is $y=7257.4 x+12415$. The average correlation coefficient value was calculated from the linearity plot drawn for series of mentioned range of concentrations for DOR, LAM and TDF is 0.9994, 0.9993, 0.9993 respectively, 
Table 1 Different trails

\begin{tabular}{|c|c|c|c|c|}
\hline Trail & Column & Mobile phase (\% v/v) & Flow rate & Observation \\
\hline 1 & $\begin{array}{l}\text { STD Hibar C18 } \\
(100 \times 2.1 \mathrm{~mm}, 2 \mu \mathrm{m})\end{array}$ & Acetonitrile:Water (50:50) & $0.3 \mathrm{~mL}$ & $\begin{array}{l}\text { Baseline noise was observed and platecount of Doravirine } \\
\text { peak was less than } 2000 \text { (1883) }\end{array}$ \\
\hline 2 & Standard Hibar C18 $(100 \times 2.1 \mathrm{~mm}, 2 \mu)$ & Methanol:Water (50:50) & $0.3 \mathrm{~mL}$ & $\begin{array}{l}\text { Tenofovir was not eluted and resolution between Doravirine } \\
\text { and Lamivudine was less than } 2\end{array}$ \\
\hline 3 & STD Hibar C18 (100 × 2.1 mm, $2 \mu \mathrm{m})$ & Acetonitrile:OPA (50:50) & $0.3 \mathrm{~mL}$ & $\begin{array}{l}\text { Doravirine peak plate count was less than } 2000 \text { (847.8) and } \\
\text { Lamivudine plate count was near to } 2000 \text { (2003.6) }\end{array}$ \\
\hline 4 & Standard SB C18 $(100 \times 2.1 \mathrm{~mm}, 2 \mu)$ & Acetonitrile: Kh2po4 (40:60) & $0.3 \mathrm{~mL}$ & Doravirine peak plate count was lessthan 2000 (1275.7) \\
\hline 5 & HSS C18 $(100 \times 2.1 \mathrm{~mm}, 2 \mu)$ & Acetonitrile: Kh2po4 (40:60) & $0.3 \mathrm{~mL}$ & $\begin{array}{l}\text { Doravirine, Lamivudine and Tenofovir disoproxil fumarate } \\
\text { were eluted at retention time of } 1.215,1.498,1.823 \mathrm{~min} \\
\text { respectively }\end{array}$ \\
\hline
\end{tabular}

$v / v$ volume by volume, STD standard, SB stable bonding, $H S S$ hollow structural sections, $m m$ millimeter, $m L$ milliliter, $\%$ percentage, $\mu m$ micrometer, OPA ortho phosphoric acid, Kh2po4 potassium dihydrogen orthophosphate buffer

Table 2 System suitability results of DOR, LAM and TDF

\begin{tabular}{llllll}
\hline Drug & Parameter & RT & Peak area & $\begin{array}{l}\text { USP Plate } \\
\text { Count }\end{array}$ & USP Tailing \\
\hline DOR & Mean & 1.227 & 269,930 & 3562 & 1.25 \\
& SD & 0.007 & 3869.6 & 65.634 & 0.023 \\
& \%RSD & 0.599 & 1.4 & 1.843 & 1.85 \\
LAM & Mean & 1.517 & $1,247,416$ & 5519.3 & 1.415 \\
& SD & 0.0098 & $15,064.42$ & 85.104 & 0.014 \\
& \%RSD & 0.645 & 1.207 & 1.54 & 0.974 \\
TDF & Mean & 1.853 & $1,143,433$ & 8462.3 & 1.405 \\
& SD & 0.0131 & $15,455.88$ & 133.04 & 0.0216 \\
& \%RSD & 0.708 & 1.4 & 1.572 & 1.54 \\
\hline
\end{tabular}

DOR Doravirine, LAM Lamivudine, TDF Tenofovir disoproxil fumarate, $S D$ standard deviation, \%RSD relative standard deviation, $R T$ retention time

which ensures linearity of the method (Fig. 3). The linearity data was given in Table 3.

\section{Sensitivity}

The LOD and LOQ values computed from the stated formulae were found to be $0.25 \mu \mathrm{g} / \mathrm{mL}$ and $0.76 \mu \mathrm{g} / \mathrm{mL}$ for DOR, $0.24 \mu \mathrm{g} / \mathrm{mL}$ and $0.73 \mu \mathrm{g} / \mathrm{mL}$ for LAM and $0.797 \mu \mathrm{g} /$ $\mathrm{mL}$ and $2.97 \mu \mathrm{g} / \mathrm{mL}$ for TDF.

\section{Solution stability}

The \%RSD of peak area responses of the DOR, LAM and TDF for $48 \mathrm{~h}$ was estimated as $\leq 2$, which ensures that the solution was stable for $72 \mathrm{~h}$ at room temperature.

\section{Specificity}

No interferences from blank and placebo was observed at the retention time of the peaks of DOR, LAM and TDF represents the specificity of the method in respect of TDF, LAM and DOR.

\section{Precision}

\%RSD for the peak area response of the DOR, LAM and TDF in multiple consecutive replicate injections of standard solution was computed as $\leq 2$ (Table 4 ), which significantly assures the precision of the proposed method.

\section{Accuracy}

The mean percentage recovery of DOR, LAM and TDF in different spiked levels (i.e., 50\%, 100\%, 150\%) were ascertained to be $100 \pm 2 \%$ (Table 5), which represents that the method is highly accurate as per $\mathrm{ICH}$ standards.

Table 3 Linear regression data of DOR, LAM and TDF

\begin{tabular}{llll}
\hline Parameters (units) & DOR & LAM & TEN \\
\hline Linearity range $(\mu \mathrm{g} / \mathrm{mL})$ & $12.5-75$ & $37.5-225$ & $37.5-225$ \\
$r^{2} \pm S D$ & $0.9992 \pm 0.000153$ & $0.9992 \pm 0.000404$ & $0.9992 \pm 0.0000577$ \\
Slope $\pm S D$ & $5478.6 \pm 16.728$ & $8436.9 \pm 19.34$ & $7257.37 \pm 15.567$ \\
Intercept $\pm S D$ & $2800.367 \pm 414.287$ & $4540 \pm 613.61$ & $12,415.33 \pm 2153.02$ \\
\hline
\end{tabular}

DOR Doravirine, LAM Lamivudine, TDF Tenofovir disoproxil fumarate, $n$ number of determinations, $\mu \mathrm{g} / \mathrm{mL}$ microgram per milliliter, $r$ correlation coefficient, $S D$ standard deviation 


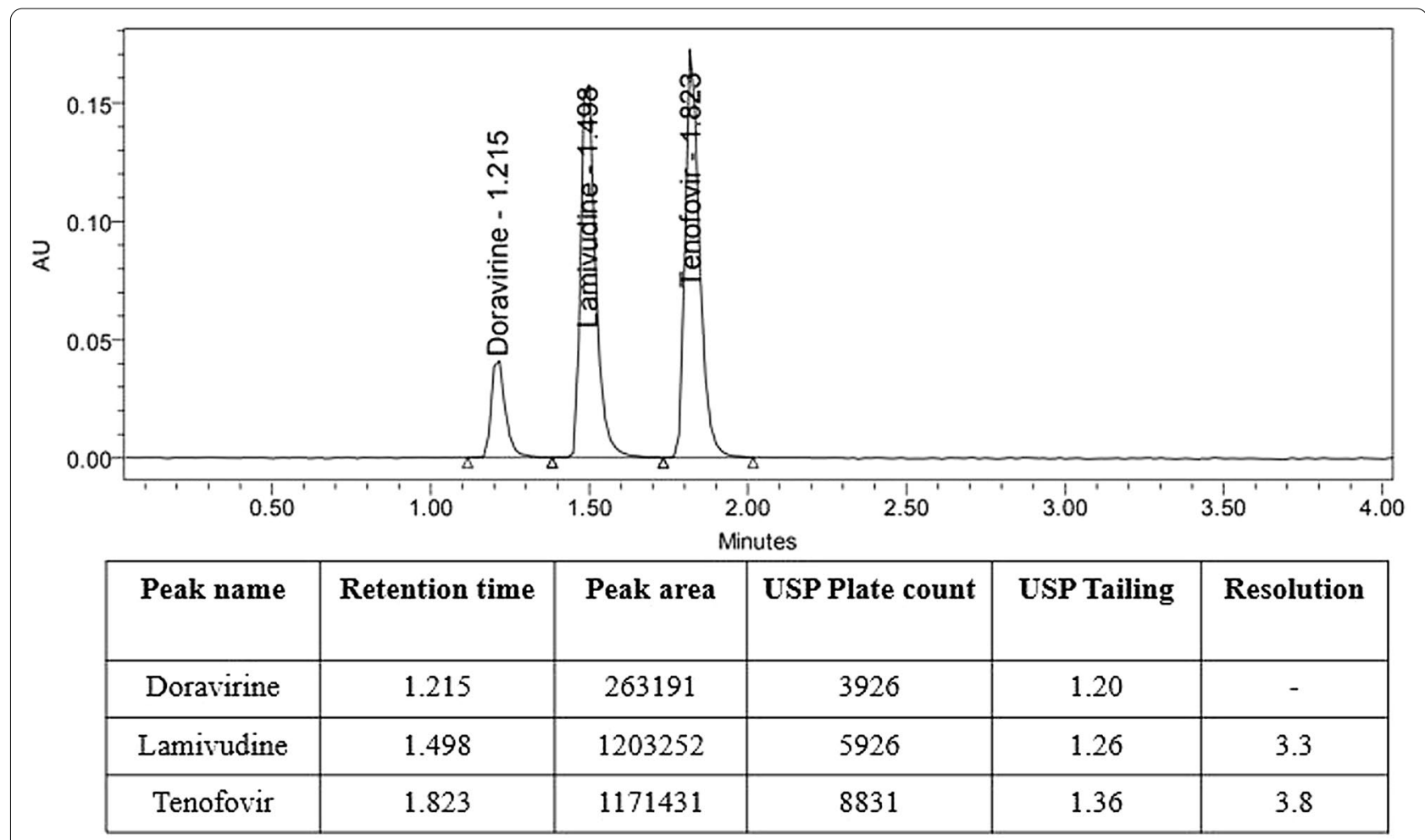

Fig. 3 Linearity curves of Doravirine, Lamivudine and Tenofovir disoproxil fumarate

Table 4 Intra-day and inter-day precision data of DOR, LAM and TDF

\begin{tabular}{lllll}
\hline Precision & S. no & DOR & LAM & \multicolumn{1}{c}{ TDF } \\
& & Peak area & Peak area \\
\hline Intraday & Injection-1 & 268,275 & $1,230,225$ & $1,172,955$ \\
& Injection-2 & 272,409 & $1,238,594$ & $1,151,322$ \\
& Injection-3 & 271,214 & $1,257,594$ & $1,130,281$ \\
& Injection-4 & 266,268 & $1,230,136$ & $1,128,429$ \\
& Injection-6 & 268,087 & $1,249,456$ & $1,143,430$ \\
& Mean & 269,788 & $1,239,040$ & $1,144,274$ \\
& SD & 2595.8 & $12,055.1$ & $16,403.3$ \\
\hline Inter-day & \%RSD & 1.0 & 1.0 & 1.4 \\
\hline Day-1 & S. no & Peak area & Peak area & Peak area \\
& Injection-1 & 257,531 & $1,177,529$ & $1,035,510$ \\
Day-2 & Injection-2 & 254,276 & $1,190,106$ & $1,016,879$ \\
& Injection-1 & 252,049 & $1,182,299$ & $1,048,079$ \\
Day-3 & Injection-2 & 260,733 & $1,172,679$ & $1,016,808$ \\
& Injection-1 & 255,549 & $1,171,575$ & $1,047,041$ \\
& Injection-2 & 255,618 & $1,178,127$ & $1,013,266$ \\
& Mean & 255,959 & $1,178,719$ & $1,029,597$ \\
& SD & 2955.2 & 0808.3 & $15,955.2$ \\
& \%RSD & 1.2 & 0.6 & 1.5 \\
\end{tabular}

S. no serial number, SD standard deviation, \%RSD relative standard deviation, $R T$ retention time, DOR Doravirine, LAM Lamivudine, TDF Tenofovir disoproxil fumarate 
Table 5 Percentage recovery results of DOR, LAM and TDF

\begin{tabular}{lllll}
\hline DRUG & $\begin{array}{l}\text { Level of addition } \\
(\%)\end{array}$ & $\begin{array}{l}\text { Amount added } \\
(\boldsymbol{\mu} \mathbf{g} / \mathbf{m L})\end{array}$ & $\begin{array}{l}\text { Drug found }(\boldsymbol{\mu g} / \mathbf{m L}) \\
\text { Mean } \pm \text { SD }\end{array}$ & $\begin{array}{l}\text { Average \% recovery } \\
\text { Mean } \pm \text { SD }\end{array}$ \\
\hline DOR & 50 & 25 & $24.93 \pm 0.222$ & $99.74 \pm 0.601$ \\
& 100 & 50 & $49.81 \pm 0.289$ & \\
& 150 & 75 & $74.91 \pm 0.385$ & $99.01 \pm 0.745$ \\
LAM & 50 & 75 & $74.103 \pm 0.791$ & \\
& 100 & 150 & $149.167 \pm 0.077$ & $100.05 \pm 0.892$ \\
TDF & 150 & 225 & $222.264 \pm 1.864$ & \\
& 50 & 75 & $75.39 \pm 0.638$ & \\
& 100 & 150 & $149.52 \pm 1.468$ & \\
\end{tabular}

DOR Doravirine, LAM Lamivudine, TDF Tenofovir disoproxil fumarate, SD standard deviation, $\% R S D$ relative standard deviation, $R T$ retention time, $\mu g / m L$ microgram per millilitre

Table 6 Robustness results of DOR, LAM and TDF

\begin{tabular}{|c|c|c|c|c|}
\hline Drug name & Variation in parameter & & $\begin{array}{l}\text { Peak area } \\
(\text { mean } \pm \text { SD) }\end{array}$ & $\%$ RSD \\
\hline \multirow[t]{6}{*}{ DOR } & Flow rate & Low & $281,144 \pm 4409.7$ & 1.6 \\
\hline & $( \pm 10 \%)$ & High & $190,472 \pm 2766.0$ & 1.5 \\
\hline & Mobile phase & Low & $230,244 \pm 3529.6$ & 1.5 \\
\hline & Ratio ( $\pm 10 \%)$ & High & $208,540 \pm 4330.2$ & 2.0 \\
\hline & Temperature $( \pm 5 \%)$ & Low & $153,867 \pm 2977.1$ & 1.9 \\
\hline & & High & $140,746 \pm 1414.8$ & 1.0 \\
\hline \multirow[t]{6}{*}{ LAM } & Flow rate $( \pm 10 \%)$ & Low & $1,303,776 \pm 24,862.5$ & 1.9 \\
\hline & & High & $880,493 \pm 8597.7$ & 1.0 \\
\hline & Mobile phase ratio ( $\pm 10 \%)$ & Low & $2,043,421 \pm 29,466.8$ & 1.4 \\
\hline & & High & $1,730,444 \pm 10,228.3$ & 0.6 \\
\hline & Temperature $( \pm 5 \%)$ & Low & $592,858 \pm 8755.3$ & 1.5 \\
\hline & & High & $584,542 \pm 9847.035$ & 1.7 \\
\hline \multirow[t]{6}{*}{ TDF } & Flow rate $( \pm 10 \%)$ & Low & $1,329,263 \pm 26,742.6$ & 2.0 \\
\hline & & High & $1,051,959 \pm 10,450.7$ & 1.0 \\
\hline & Mobile phase Ratio $( \pm 10 \%)$ & Low & $1,135,591 \pm 15,566.02$ & 1.4 \\
\hline & & High & $1,010,700 \pm 6822.4$ & 0.7 \\
\hline & Temperature $( \pm 5 \%)$ & Low & $614,440 \pm 8254.7$ & 1.3 \\
\hline & & High & $594,030 \pm 8543.4$ & 1.4 \\
\hline
\end{tabular}

DOR Doravirine, LAM Lamivudine, TDF Tenofovir disoproxil fumarate, SD standard deviation, \%RSD relative standard deviation

\section{Robustness}

Deliberate changes applied to certain method conditions like temperature, flow rate and mobile phase ratio did not affect the system suitability parameters (\%RSD less than 2 ), which significantly represents that robustness of the method. Robustness data was shown in Table 6.

\section{Stability indicating studies}

As per researcher view, with the application of different stress conditions up to $20 \%$ degradation is effective in stability representing methods $[31,32]$. The percentage of drug degraded in different stress conditions was evaluated from the obtained chromatogram peak areas of 
Table 7 Summary of degradation data of DOR, LAM and TDF

\begin{tabular}{|c|c|c|c|c|c|c|}
\hline \multirow[t]{2}{*}{ Degradation condition } & \multicolumn{2}{|l|}{ DOR } & \multicolumn{2}{|l|}{ LAM } & \multicolumn{2}{|l|}{ TDF } \\
\hline & $\%$ Deg & Peak area & $\%$ Deg & Peak area & $\%$ Deg & Peak area \\
\hline Acid $\left(0.5 \mathrm{~N} / 60^{\circ} \mathrm{C} / 1 \mathrm{~h}\right)$ & 4.05 & 258,342 & 4.77 & $1,190,261$ & 5.19 & $1,085,169$ \\
\hline Base $\left(0.5 \mathrm{~N} / 60^{\circ} \mathrm{C} / 1 \mathrm{~h}\right)$ & 3.12 & 260,826 & 5.74 & $1,178,182$ & 4.84 & $1,089,142$ \\
\hline Oxidative $\left(10 \% \mathrm{w} / \mathrm{v} \mathrm{H}_{2} \mathrm{O}_{2} / 60^{\circ} \mathrm{C} / 1 \mathrm{~h}\right)$ & 3.54 & 259,703 & 4.91 & $1,188,582$ & 4.83 & $1,089,342$ \\
\hline Hydrolytic (water/60 $\mathrm{C} / 1 \mathrm{~h}$ ) & 1.01 & 266,531 & 0.87 & $1,239,093$ & 0.63 & $1,137,391$ \\
\hline Thermal $\left(105^{\circ} \mathrm{C} / 1\right.$ day $)$ & 1.72 & 264,614 & 1.09 & $1,236,328$ & 1.02 & $1,132,940$ \\
\hline $\begin{array}{l}\text { Photolytic (UV radiation at } 200-\mathrm{Wh} / \mathrm{m}^{2} \text {-dark } \\
\text { control) }\end{array}$ & 2.49 & 262,531 & 1.83 & $1,227,093$ & 2.03 & $1,121,391$ \\
\hline
\end{tabular}

DOR Doravirine, LAM Lamivudine, TDF Tenofovir disoproxil fumarate, $h$ hours, \% percentage, UV ultraviolet, min minute, $N$ normality, ${ }^{\circ} \mathrm{C}$ degree celsius, $W h / \mathrm{m}^{2}$ watthour per square metre, $\%$ Deg percentage degradation

DOR, LAM and TDF in both standard and stressed solution. The percentage degradation data of different three analytes were given in Table 7 and concerned chromatograms were represented in Figs. 4, 5, 6, 7, 8, and 9.

\section{Application of the method to marketed formulation}

The percentage purity of the DOR, LAM and TDF in commercial tablets was estimated to be $100 \% \pm 10$ (Table 8) [33], which indicate that the obtained assay values of DOR, LAM and TDF Were in obedience with the ICH limits. The recorded chromatogram of sample solution was shown in Fig. 10.

\section{Discussion}

Proficient and extensive literature survey reveals that no UPLC and two HPLC methods were observed for the estimation of mixture of DOR, LAM and TDF in pure form and in marketed formulation. In the reported HPLC methods, DOR and TDF were eluted at longer retention time and these methods were not considered as economical methods because of low sensitivity and more mobile phase consumption $[27,28]$. UPLC when compared with HPLC, has a packed column with less particle size which provides large surface area for analytes to interact and aids in faster elution of analytes and efficiency in separation of analytes. Hence to overcome the drawbacks of HPLC an attempt was made to develop an effective

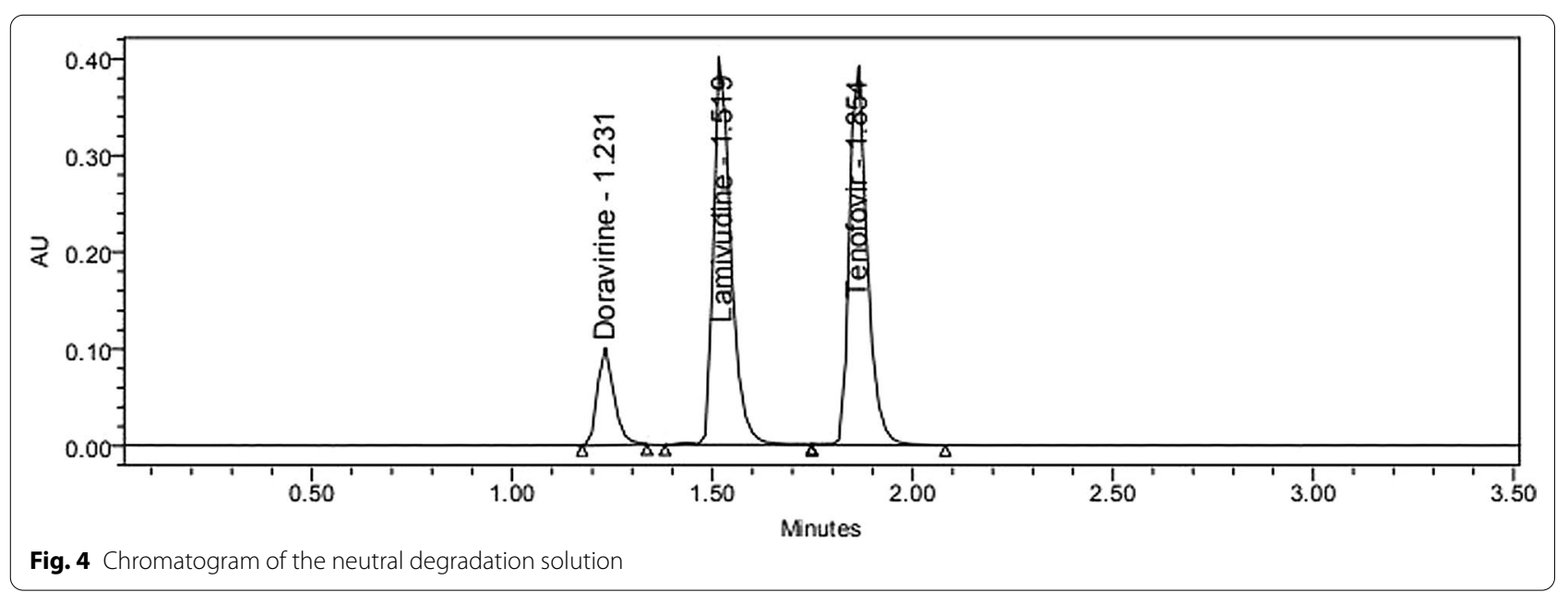




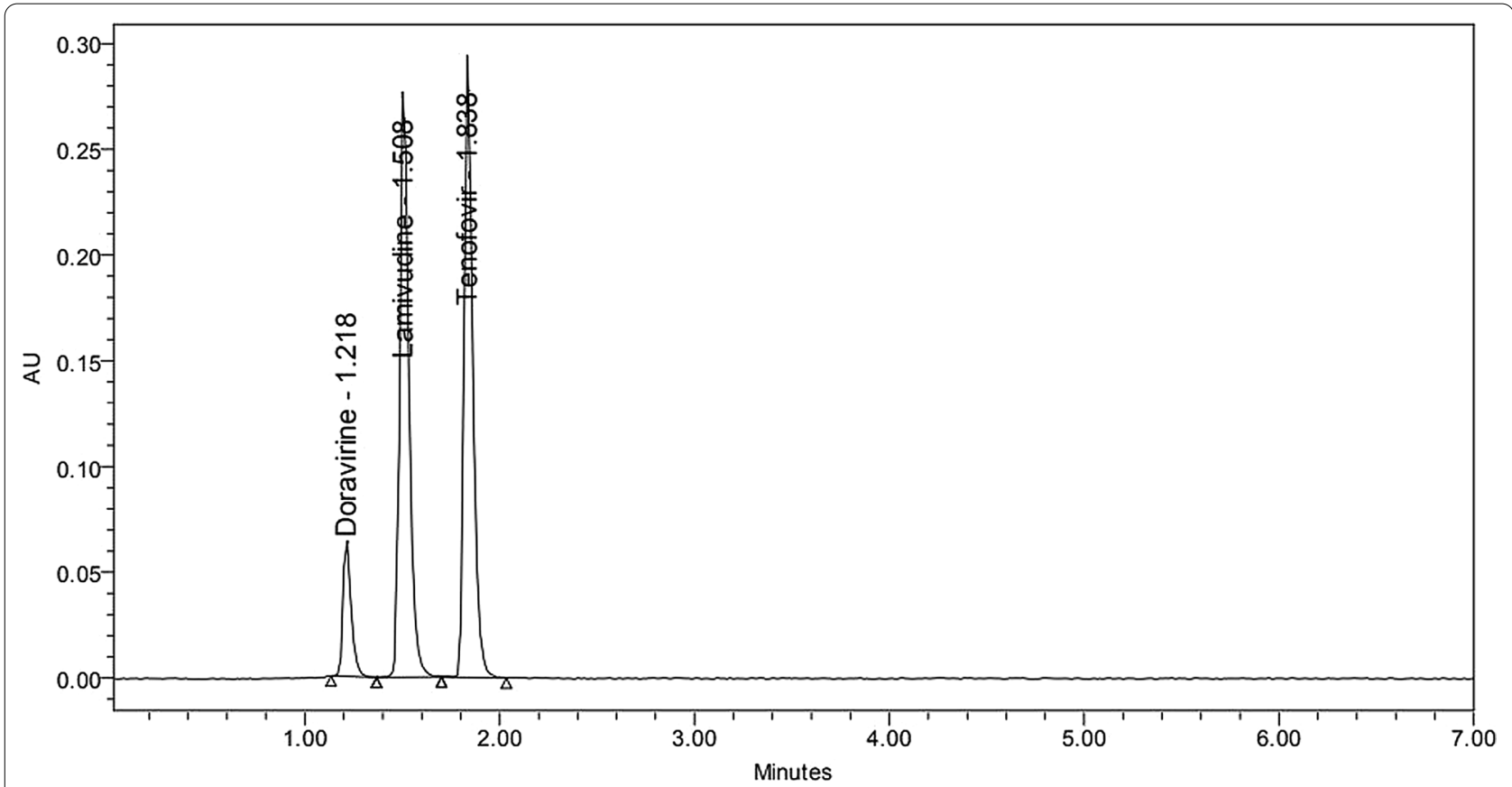

Fig. 5 Chromatogram of the marketed formulation

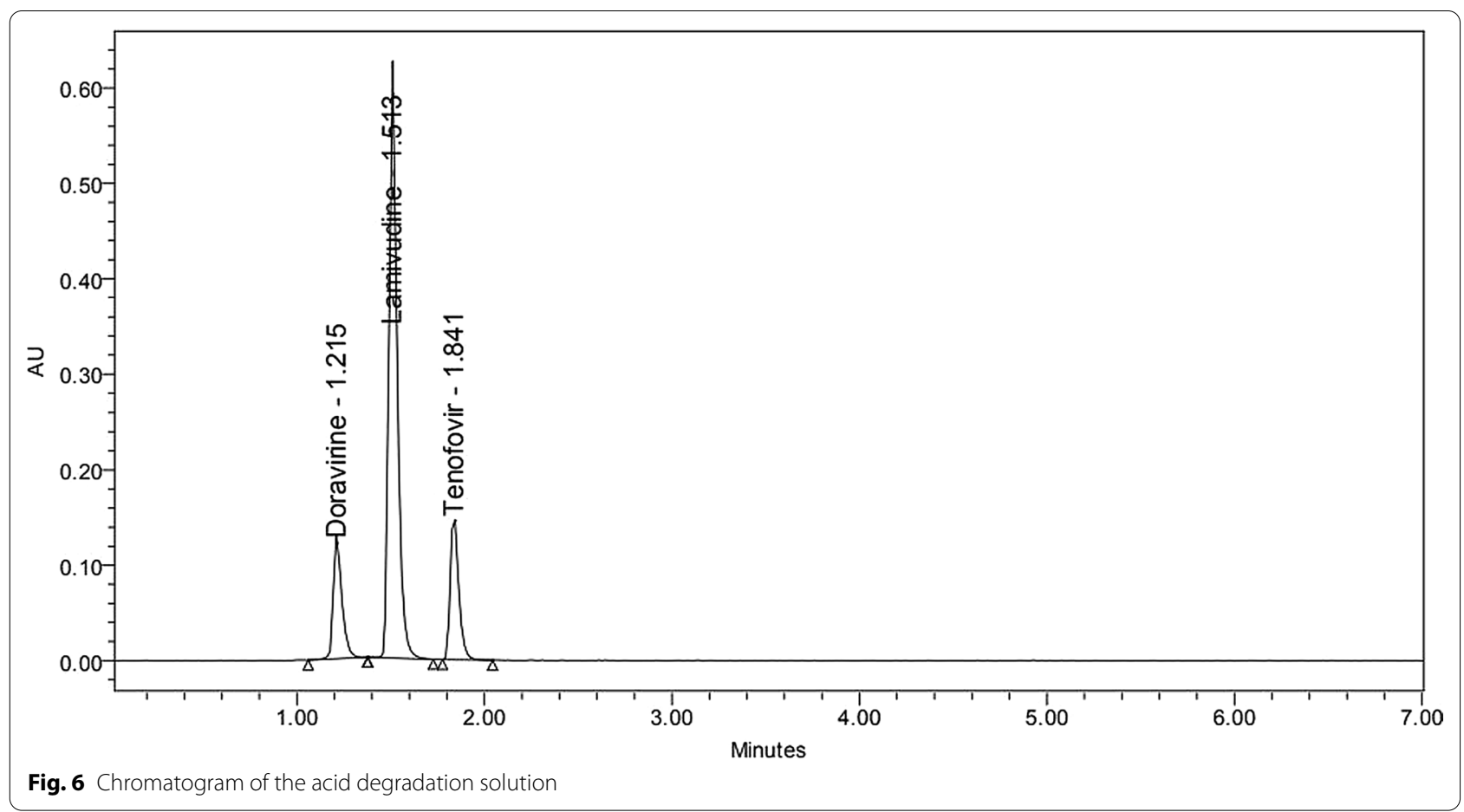




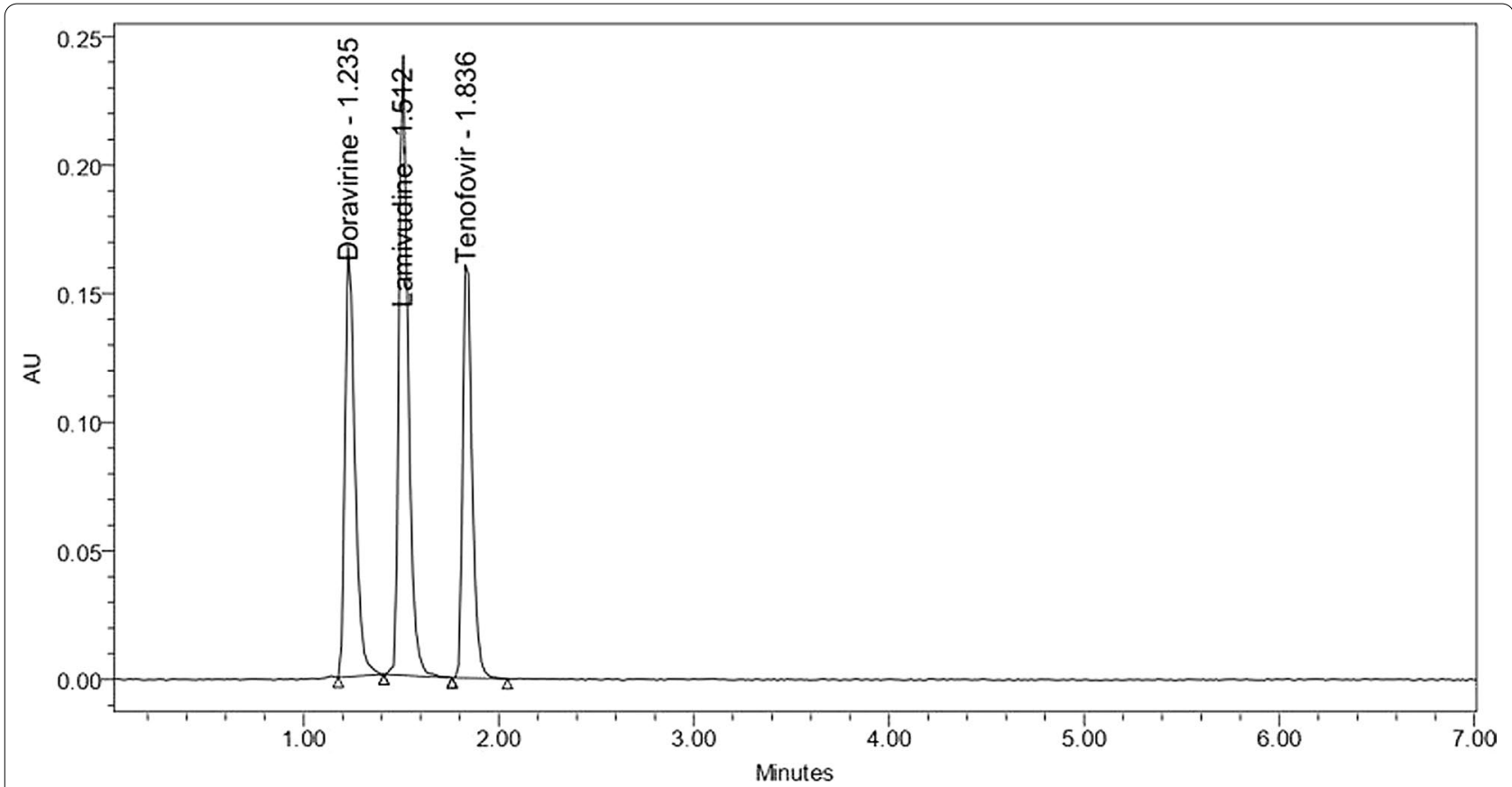

Fig. 7 Chromatogram of the alkaline degradation solution

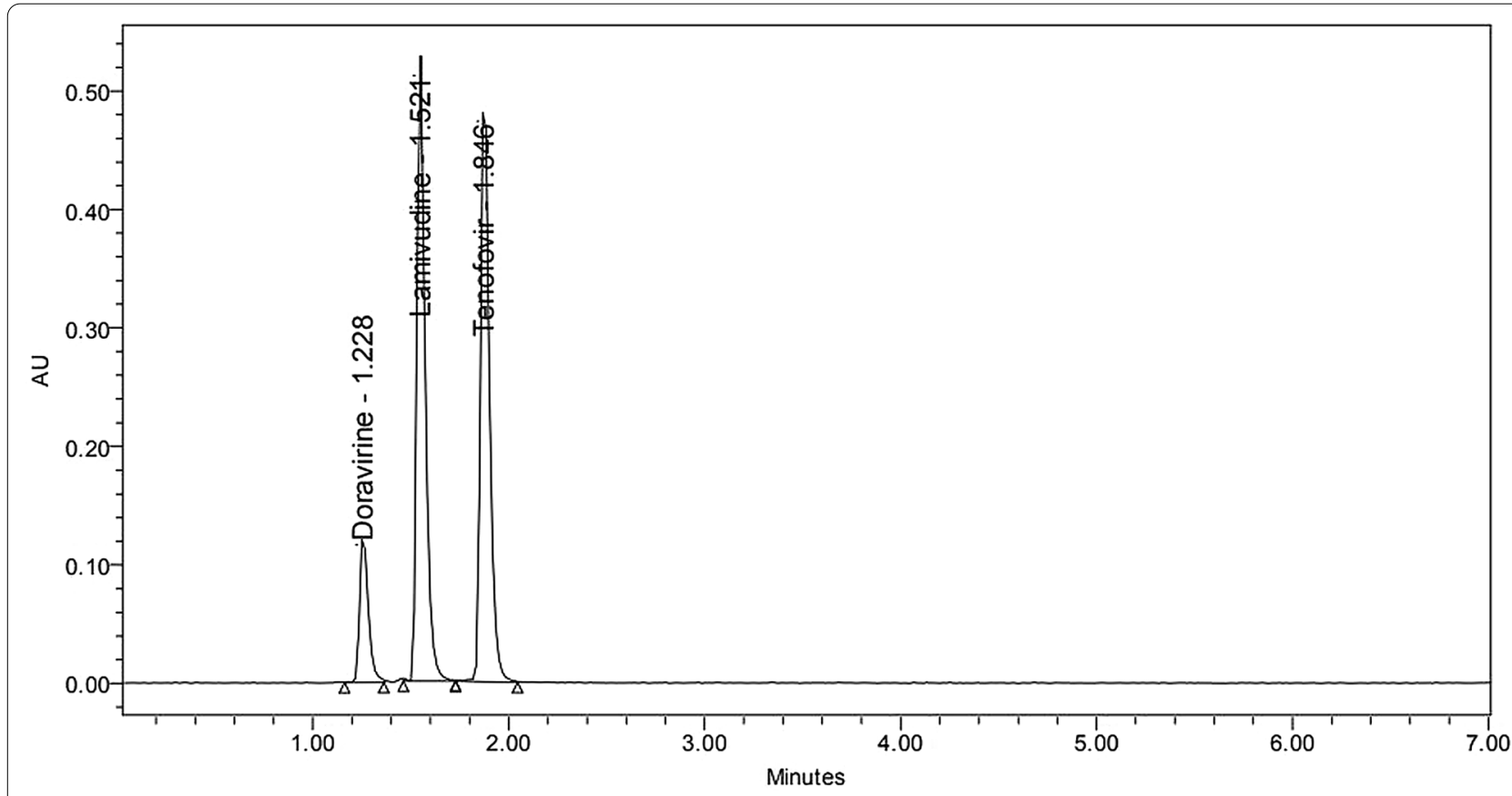

Fig. 8 Chromatogram of the oxidative degradation solution 
Table 8 Results of \%assay of tablet dosage form

\begin{tabular}{lllll}
\hline Drug & Peak name & Peak area & Label claim & \%assay \\
\hline DOR & Standard & 269,930 & 100 & 98.8 \\
& Test & 267,191 & & \\
LMV & Standard & $1,247,416$ & 300 & 98.7 \\
& Test & $1,233,252$ & & \\
TDF & Standard & $1,143,433$ & 300 & 99.72 \\
& Test & $1,141,431$ & & \\
\hline
\end{tabular}

DOR Doravirine, LAM Lamivudine, TDF Tenofovir disoproxil fumarate, $\%$ percentage

RP-UPLC method with more sensitivity and faster elution of elution of analytes with short retention time. In the proposed method a simple mobile phase composition of $0.01 \mathrm{~N}$ Potassium dihydrogen ortho phosphate and $\mathrm{ACN}$ in $(60: 40 \mathrm{v} / \mathrm{v})$ ratio was selected for analysis of three drug analytes and DOR, LAM and TDF were eluted at retention time of $1.2 \mathrm{~min}, 1.4 \mathrm{~min}$ and $1.8 \mathrm{~min}$ respectively. The current developed method was cost-effective with less retention time and simple mobile phase composition when compared with the reported HPLC methods.
More number of samples can be investigated rapidly by using the current method. The statistical data obtained from various validation parameters represents that the current method has ideal specificity, perfect accuracy and reproducible precision with more sensitivity.

\section{Conclusions}

A simple, economical and cost-effective RP-UPLC method was established with reproducible precision and superior sensitivity for simultaneous estimation of DOR, LAM and TDF in pure bulk form and their combined film coated tablet form. Investigation of the DOR, LAM and TDF under various stress conditions indicate the stability indication parameter of the method. The method was competently separate DOR, LAM, TDF and the percentage degradation of the respective drugs was evaluated from the recorded chromatograms under various stress conditions. Therefore, the present method has remarkable recognition in the industrial sector for estimation of the DOR, LAM, TDF in the marketed formulation.

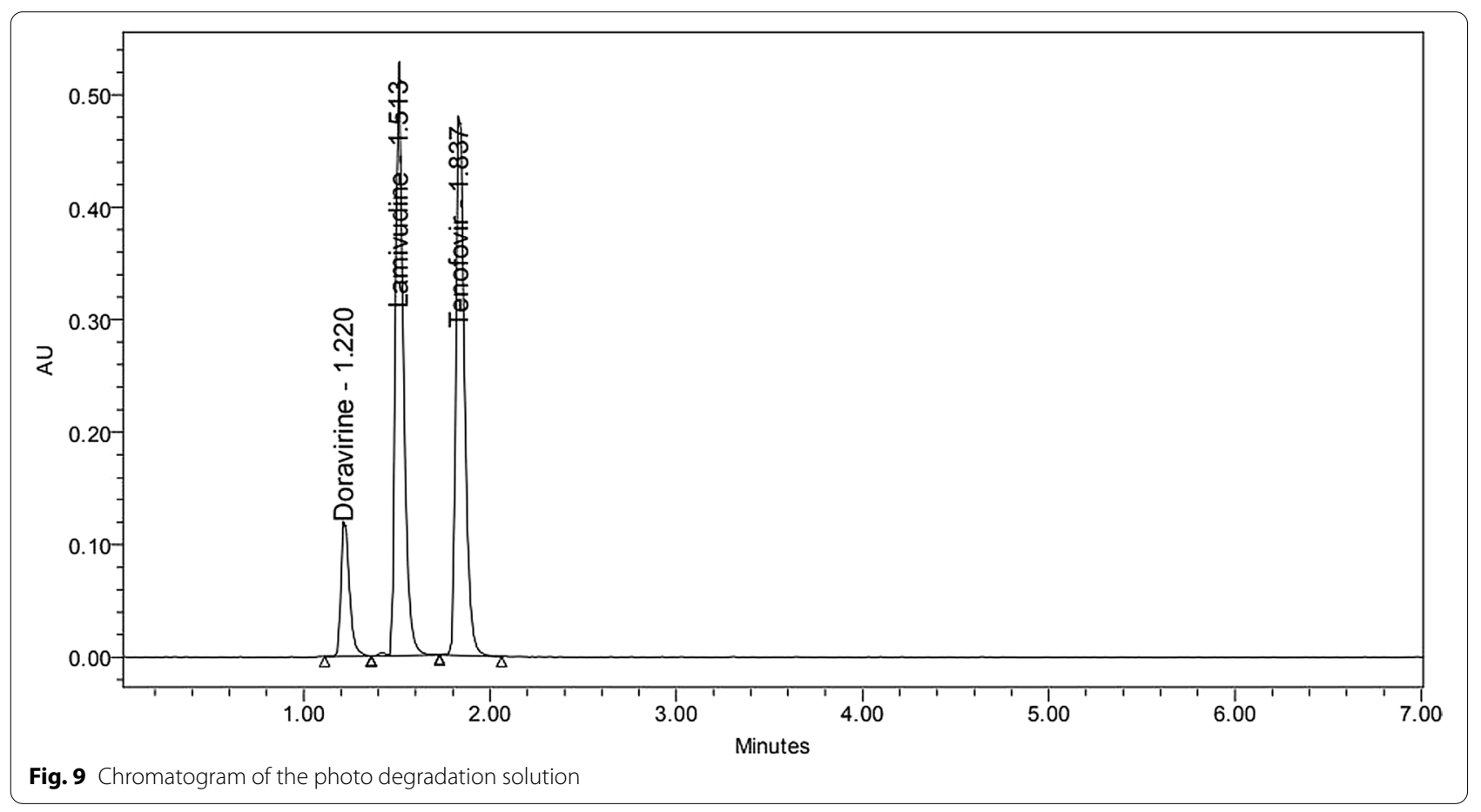




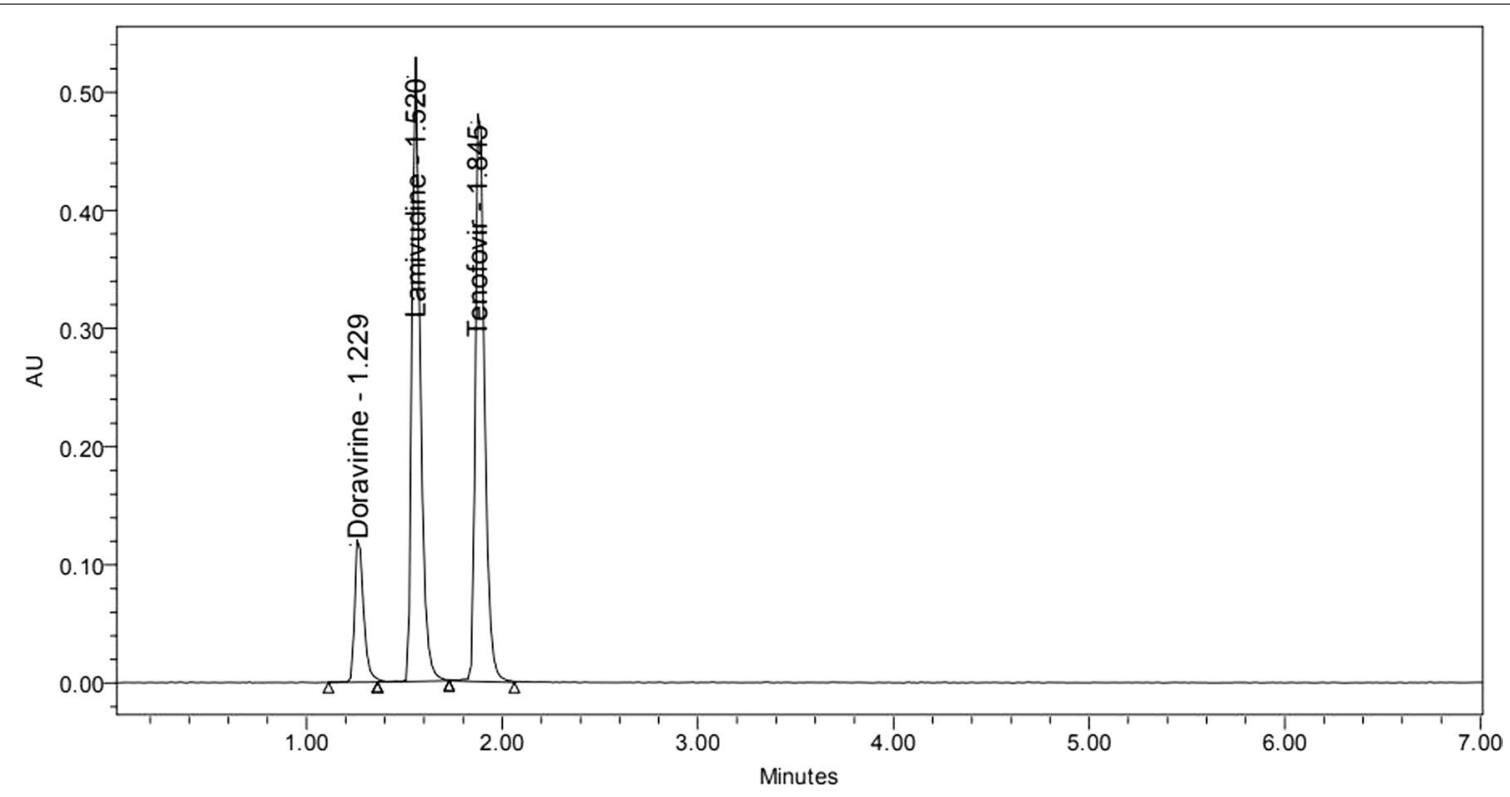

Fig. 10 Chromatogram of the thermal solution

\section{Abbreviations}

DOR: Doravirine; LAM: Lamivudine; TDF: Tenofovir disoproxil fumarate; RT: Retention time; LOD: Limit of detection; LOQ: Limit of quantification; SD: Standard deviation; RSD: Relative standard deviation.

\section{Acknowledgements}

The authors gratefully acknowledge the Spectrum Pharma Research Solutions, Hyderabad, for providing drug samples, to carry forward the research work.

\section{Authors' contributions}

SA analyzed and interpreted the data of obtained chromatograms and a major contributor in writing the manuscript. RB performed the bench work and experimental work of the stability indicating liquid chromatographic method development of analytes using UPLC. Both authors read and approved the final manuscript.

\section{Funding}

It is self-financed, funding was not sponsored by any organization, funding agency and non-profit research bodies.

\section{Availability of data and materials}

All data and material should be available upon request.

\section{Declarations}

\section{Ethics approval consent to participate}

Not applicable.

\section{Consent for publication}

Not applicable.

\section{Competing interests}

No competing interests to declare.

\section{Author details}

'Department of Pharmaceutical Analysis, IPT, SPMVV, Tirupati, Andhra Pradesh 517501, India. ${ }^{2}$ Department of Pharmacognosy, IPT, SPMVV, Tirupati, Andhra Pradesh 517501, India
Received: 1 August 2021 Accepted: 29 September 2021

Published online: 03 November 2021

\section{References}

1. Colombier M-A, Molina J-M (2018) Doravirine: a review. Curr Opin HIV AIDS 13:308-314. https://doi.org/10.1097/COH.0000000000000471

2. Rock AE, Lerner J, Badowski ME (2020) Doravirine and its potential in the treatment of HIV: an evidence-based review of the emerging data. HIV AIDS (Auckl) 12:201-210. https://doi.org/10.2147/HIV.S184018

3. Pham HT, Xiao MA, Principe MA, Wong A, Mesplède T (2020) Pharmaceutical, clinical, and resistance information on doravirine, a novel non-nucleoside reverse transcriptase inhibitor for the treatment of HIV-1 infection. Drugs Context. https://doi.org/10.7573/dic.2019-11-4

4. Luo A, Jiang X, Ren H (2018) Lamivudine plus tenofovir combination therapy versus lamivudine monotherapy for HBV/HIV coinfection: a metaanalysis. Virol J 15:139. https://doi.org/10.1186/s12985-018-1050-3

5. Quercia R, Perno C-F, Koteff J, Moore K, McCoig C, Clair M (2018) Twentyfive years of lamivudine: current and future use for the treatment of HIV-1 infection. J Acquir Immune Defic Syndr 78:125-135. https://doi.org/10. 1097/QAI.0000000000001660

6. Anderson PL, Rower JE (2010) Zidovudine and lamivudine for HIV infection. Clin Med Rev Ther 2:a2004

7. Lyseng-Williamson KA, Reynolds NA, Plosker GL (2005) Tenofovir disoproxil fumarate: a review of its use in the management of HIV infection. Drugs 65:413-432. https://doi.org/10.2165/00003495-200565030-00006

8. Badii VS, Buabeng KO, Agyarko Poku T, Forkuo AD, Boamah BB, Arhin SM (2018) Tenofovir-based highly active antiretroviral therapy is associated with superior CD4 T cells repopulation compared to zidovudine-based HAART in HIV 1 infected adults. Int J Chronic Dis. https://doi.org/10.1155/ 2018/3702740

9. Ustianowski A, Arends JE (2015) Tenofovir: what we have learnt after 7.5 million person-years of use. Infect Dis Ther 4:145-157. https://doi.org/10. 1007/s40121-015-0070-1

10. Godela R, Sowjanya G (2020) An effective stability indicating RP-HPLC method for simultaneous estimation of Dolutegravir and Lamivudine in bulk and their tablet dosage form. Future J Pharm Sci 6:9. https://doi.org/ 10.1186/s43094-020-00026-0

11. Karishma S, Subramaniam S, Muthuraman MS, Sivasubramanian A (2013) RP-HPLC analytical method development and validation for lamivudine 
and zidovudine in pharmaceutical dosage forms. Int J Pharmtech Res 5:1321-1331

12. Pal N, Avanapu SR, Ravikumar P (2016) Simultaneous HPLC method development and validation for estimation of Lamivudine, Abacavir and Dolutegravir in combined dosage form with their stability studies. Asian J Chem 28:273-276. https://doi.org/10.14233/ajchem.2016.19116

13. Nalini NC, Nithya A, Afreen A, Banu AA, Hemalatha P, Gayathri EJ (2018) Analytical methods for determination of lamivudine and their applicability in biological studies. Res J Pharm Technol 11:5166-5172. https://doi. org/10.5958/0974-360X.2018.00944.7

14. Venkatesh P, Daggumati M (2012) Development and validation of a normal-phase HPTLC method for the simultaneous analysis of Lamivudine and Zidovudine in fixed-dose combination tablets. J Pharm Anal 2:152-155. https://doi.org/10.1016/j.jpha.2011.11.002

15. Nandi U, Das A, Roy B, Choudhury H, Gorain B, Pal TK (2013) Development and validation of an HPLC-UV method for simultaneous determination of zidovudine, lamivudine, and nevirapine in human plasma and its application to pharmacokinetic study in human volunteers. Drug Test Anal 5:485-491. https://doi.org/10.1002/dta.419

16. Ramaswamy A, Arul Gnana Dhas AS (2018) Development and validation of analytical method for quantitation of Emtricitabine, Tenofovir, Efavirenz based on HPLC. Arab J Chem 11:275-281. https://doi.org/10.1016/j. arabjc.2014.08.007

17. GuY, Zeng B, Sherma J (2019) Development of quantitative HPTLC methods for dolutegravir, lamivudine, and tenofovir disproxil fumarate in a combination pharmaceutical product using a model process published earlier for transfer of minilab TLC screening methods to HPTLC-densitometry. Acta Chromatogr 32:199-202. https://doi.org/10.1556/1326.2019. 00689

18. Nekkala K, Kumar VS, Ramachandran D (2017) Development and validation for the simultaneous estimation of lamivudine, tenofovir disproxil and dolutegravir in drug product by RP-HPLC. J Pharm Sci 9:1505-1510

19. Jagadabi V, Nagendra Kumar P, Pamidi S, Ramaprasad L, Nagaraju D (2018) A stability-indicating HPLC method for the determination of potential impurities in a new fixed dose combination of dolutegravir, lamivudine and tenofovir disoproxil fumarate tablets used in the first line treatment of hiv-1 infection. Int Res J Pharm 9:65-74. https://doi.org/10. 7897/2230-8407.09575

20. More S, Tandulwadkar S, Nikam A, Rathore A, Lohidasan S, Mahadik K (2013) Separation and determination of lamivudine, tenofovir disoproxil fumarate and efavirenz in tablet dosage form by thin-layer chromatographic-densitometric method. J Planar Chromatogr Mod TLC 26:78-85

21. Mallikarjuna Rao N, Gowri Sankar D (2015) Development and validation of stability-indicating HPLC method for simeltaneous determination of Lamivudine, Tenofovir, and Dolutegravir in bulk and their tablet dosage form. Future J Pharm Sci 1:73-77. https://doi.org/10.1016/j.fjps.2015.11. 002

22. Anandakumar K, Abirami G, Murugan S, Ashok B (2013) RP-HPLC method for simultaneous estimation of lamivudine, tenofovir disoproxil fumarate and efavirenz in tablet formulation. J Anal Chem 68:815-821. https://doi. org/10.1134/S1061934813090025

23. Bhavsar DS, Patel BN, Patel CN (2012) RP-HPLC method for simultaneous estimation of tenofovir disoproxil fumarate, lamivudine, and efavirenz in combined tablet dosage form. Pharm Methods 3:73-78. https://doi.org/ 10.4103/2229-4708.103876

24. Sharma R, Mehta K (2010) Simultaneous spectrophotometric estimation of tenofovir disoproxil fumarate and lamivudine in three component tablet formulation containing efavirenz. Indian J Pharm Sci 72:527. https:// doi.org/10.4103/0250-474X.73926

25. Babu C, Devanna N, Reddy KVNS (2017) Validated gradient stability indicating RP-HPLC method for the simultaneous quantification of 11 related substances in the combined dosage forms of Lamivudine and Tenofovir Disopeoxil Fumarate. Int J Appl Pharm 9:61-68. https://doi.org/10.22159/ ijap.2017v9i4.19001

26. Vaikosen EN, Kashimawo AJ, Soyinka JO, Orubu S, Elei S, Ebeshi BU (2020) Simple thin layer chromatography-ultraviolet spectrophotometric method for quality assessment of binary fixed-dose-combinations of lamivudine/tenofovir disoproxil fumarate and lamivudine/zidovudine in tablet formulations. J Sep Sci 43:2228-2239. https://doi.org/10.1002/jssc. 201901117

27. Gollu G, Gummadi S (2020) Simultaneous quantification of lamivudine, tenofovir disoproxil fumarate and doravirine in pharmaceutical dosage form by liquid chromatography with diode array detection. Pharm Chem J 54:526-535. https://doi.org/10.1007/s11094-020-02232-9

28. Tiruveedhi VLNBG, Battula VR, Bonige KB (2021) RP-HPLC (stabilityindicating) based assay method for the simultaneous estimation of doravirine, tenofovir disoproxil fumarate and lamivudine. Int J Appl Pharm 13:153-159. https://doi.org/10.22159/ijap.2021v13i1.39608

29. ICH. Quality Guidelines ICH. https://www.ich.org/page/quality-guidelines Accessed 18 Jan 2021

30. FDA/CDER/"Beers D (2015) Analytical procedures and methods validation for drugs and biologics, $\mathrm{p} 18$

31. Blessy M, Patel RD, Prajapati PN, Agrawal YK (2014) Development of forced degradation and stability indicating studies of drugs_-a review. J Pharm Anal 4:159-165. https://doi.org/10.1016/j.jpha.2013.09.003

32. Hotha KK, Reddy SPK, Raju VK, Ravindranath LK (2013) Forced degradation studies: practical approach —overview of regulatory guidance and literature for the drug products and drug substances. Int Res J Pharm 4:78-85. https://doi.org/10.7897/2230-8407.04517

33. Pharmacopoeia B (2016) British Pharmacopoeia 2016. https://www. pharmacopoeia.com/the-british-pharmacopoeia. Accessed 27 Jan 2021

\section{Publisher's Note}

Springer Nature remains neutral with regard to jurisdictional claims in published maps and institutional affiliations.

\section{Submit your manuscript to a SpringerOpen ${ }^{\odot}$ journal and benefit from:}

- Convenient online submission

- Rigorous peer review

- Open access: articles freely available online

- High visibility within the field

- Retaining the copyright to your article

Submit your next manuscript at $\boldsymbol{\nabla}$ springeropen.com 